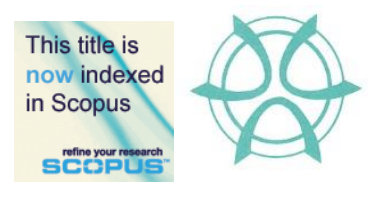

PLANNING MALAYSIA:

Journal of the Malaysian Institute of Planners

SPECIAL ISSUE V (2016), Page 129 - 144

\title{
ENERGY EFFICIENCY POLICY FOR EXISTING TYPICAL CAMPUS BUILDINGS IN THE UNIVERSITY OF MALAYA
}

\author{
Muhammad Azzam Ismail ${ }^{1}$, Karam M. Al-Obaidi ${ }^{2}, \&$ Raha Sulaiman $^{3}$ \\ ${ }^{1,2,3}$ Centre for Building, Construction and Tropical Architecture \\ Faculty of Built Environment \\ UNIVERSITY OF MALAYA
}

\begin{abstract}
A very large component of the maintenance cost of any real estate property is the electricity consumption cost. The electricity consumption cost of a 700-acre university campus in Malaysia would reach an overall yearly operating expenditure of nearly RM 1 billion. Knowing this fact, the University of Malaya's (UM) top management has conducted many projects at various scales to address energy efficiency (EE), including the replacement of old and inefficient mechanical and electrical (M\&E) equipment and the installation of new EE technologies around the campus. In enhancing the overall EE effort, an energy management system is required to ensure that a calculated EE plan can be implemented and audited after it is completed to improve the overall sustainability of UM. Therefore, this study presents the formulation of an Energy Management System (EMS) for UM based on the ASEAN Energy Management Scheme (AEMAS) methodology. Results show that with the full support of the top management of the university, the EMS can be implemented with at least a $5 \%$ electricity consumption reduction per year. The formalization of the EMS is the most important step in ensuring any marked reduction in electricity consumption campus-wide.
\end{abstract}

Keyword: Energy management system, energy efficiency, university campus 
Muhammad Azzam Ismail, Karam M. Al-Obaidi \& Raha Sulaiman

Energy Efficiency Policy for Existing Typical Campus Buildings in the University of Malaya

\section{INTRODUCTION AND BACKGROUND}

In many respects, university and college campuses are microcosms of environmental issues, concerns, and challenges. With a smaller scale and better structuring, universities are less complex than they are at the scale of the city. Universities with a potential site can implement sustainable development (Marans \& Edelstein, 2010). According to Levy and Marans (2012), many universities in the United States have undertaken large-scale environmental sustainability efforts. However, only a few have advanced broad plans to address environmental sustainability in their campuses. Numerous studies showed that universities all over the world are confronted with increasing utility costs rising significantly faster than the rate of inflation (Marans \& Edelstein, 2010). These issues are pushing university leaders to take serious decisions with long-term implications. As a result, many options are taken to overcome these concerns, such as cutbacks in building maintenance; curtailing the building of new classrooms, laboratories, and libraries; updating older facilities; reductions in faculty and staff salaries; increased student fees; and reduced student financial assistance (Marans \& Edelstein, 2010). Therefore, many universities are developing new "sustainability" programs to address the problem of their rising energy costs (Hignite, 2008).

Electricity is a key energy source and is essential for economic development in every country. The actual scenario in Peninsular Malaysia shows that every 1 kilowatt-hour $(\mathrm{kWh})$ of electricity releases about $0.681 \mathrm{~kg}$ of $\mathrm{CO}_{2}$, which is equivalent to $35 \%$ electricity supply efficiency (PTM \& DANIDA, 2006). Over the past few years, the electricity tariff for "Medium Voltage General Commercial" clients or Tenaga Nasional Berhad (TNB) tariff C1 has increased consistently. In 2007, the $\mathrm{C} 1$ tariff for every kilowatt of maximum demand was MYR19.50, and the general C1 tariff for all kilowatts of consumption was at MYR23.40. However, since January 2014, these demands have risen to MYR30.30 and MYR36.50, putting significant pressure on the monthly utility bills for the University of Malaya (UM).

Therefore, in 2012, through the sustainability drive by the UMCARES, a small group of academicians were called upon to work with the Malaysian Green Technology Corporation (MGTC) through a UM Sustainability Science Cluster (SUSCI) flagship project to test and further develop a city-level carbon emission calculator called the "Low Carbon Cities Framework" or LCCF. Eventually, UM signed a Memorandum of Understanding with the MGTC at the IGEM 2013 as a pilot partner to further develop LCCF. In addition to the LCCF flagship project and with the support of the Vice Chancellor, SUSCI initiated the UM Energy Management Initiatives (UMEMI) and sent 20 individuals selected from various levels of the university service, including academicians and technical and administrative staff, to the ASEAN Energy Management Scheme (AEMAS) energy management training in August 2013. At that point, the UM naturally 
PLANNING MALAYSIA

Sustainable Urban Development

created an energy efficiency policy, set up an energy management procedure, and allowed for existing buildings to be turned into living laboratories to test new technologies developed on campus that resulted in resource consumption efficiency.

However, the momentum stalled, and until now, only marquee energy efficiency projects were adopted such as LED streetlights fitted throughout almost the whole campus and all new buildings having energy efficient features without any systemic changes to the management of the university. The accounting of energy and water consumption continued as previously conducted, but the sharing of such information with the campus community has been inconsistent. Nevertheless, the foundations have been laid, and further action is needed especially a clear energy efficiency policy that has been outlined in this paper.

\section{RESEARCH METHODOLOGY}

As part of the efforts to achieve a marked reduction in the campus-wide electricity consumption to and formalize an effective EE policy, a set of objectives are needed:

- To implement the UM Sustainable Energy Management Program (SEMP) to increase the effectiveness of the UMEMI initiated by the UM SUSCI

- To strengthen the energy management procedure and organizational structure

- To implement appropriate measures of reducing energy consumption

To achieve the objectives stated, this study proposes that the AEMAS Energy Management Working Procedure (EM-WP) is adopted and adapted to suit the existing UM management structure. In this study, the plan for the EM-WP is presented in the next section, together with a simple case study of a faculty that includes a study on the return of investment (ROI) of the implemented measures. In demonstrating the applicability of the energy efficiency proposed in this study, the low cost measures outlined in this study can be implemented on the existing buildings in the university's campus. After one year of this initial implementation of this policy, the medium cost and high cost such as alternation to the building fabric and refreshment of cooling systems can be done to achieve a significantly high reduction of energy consumption. The flowchart (Figure 1) below indicates the process of UM in formulating an attainable energy efficiency (EE) effort.

Initially, one academic staff was approached by the researchers to solicit some energy policy information. Thereafter, the researchers referred to two technical staff members at the UM estate management department. Basing on these interviews, the researchers managed to plot the profile of the UM's Energy Management Matrix (EMM), which is presented in the next section. Additional in-depth interviews were not conducted because of the saturated response from 
Muhammad Azzam Ismail, Karam M. Al-Obaidi \& Raha Sulaiman

Energy Efficiency Policy for Existing Typical Campus Buildings in the University of Malaya

the interviewee stating that the energy policy in the UM campus has low implementation.

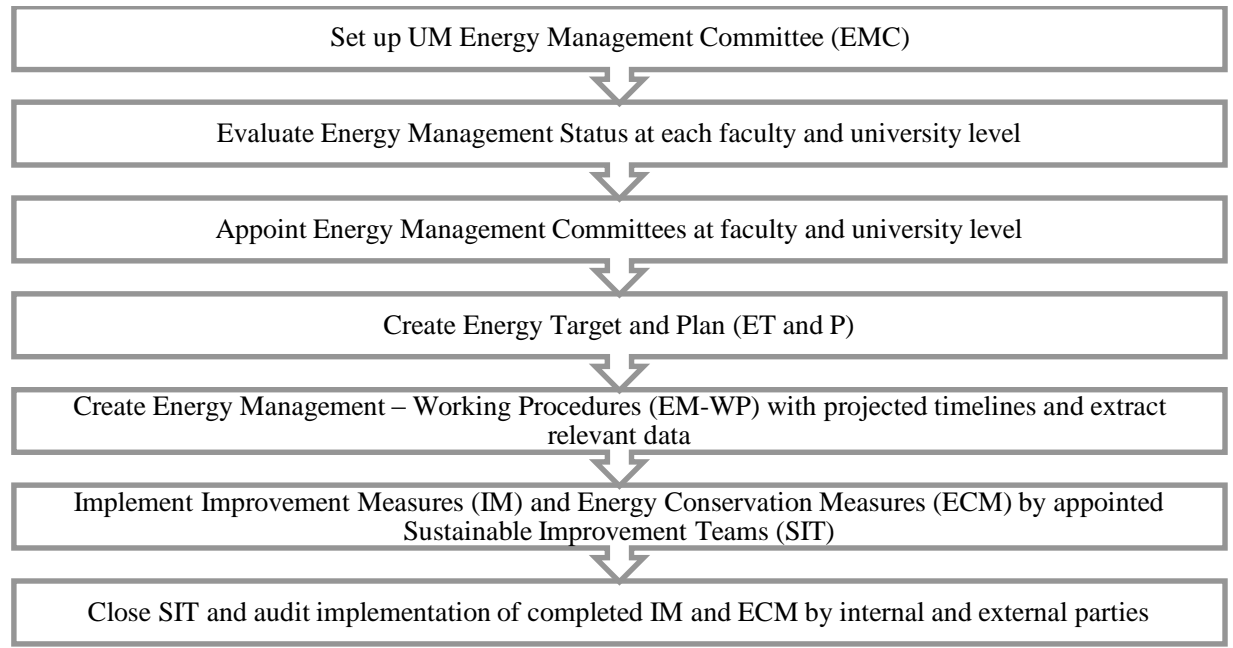

Figure 1: Implementation of Sustainable Energy Management Program (SEMP)

\section{EVALUATION OF THE ENERGY MANAGEMENT STATUS}

As mentioned earlier, through unstructured interviews, the researchers were able to plot the Energy Management Matrix as formulated by the AEMAS for UM. Initially, the foundation for UM's energy management was already established. However, according to all interviewees, it lacked clear direction and commitment from relevant parties. The existing matrix levels are indicated in Figure 2.

Each EMM represents $25 \%$ out of 100\% scores. For example, Level 1 in Energy Policy represents 25\%, and an improvement up to Level 4 is calculated to an increase of $75 \%$. In totality, the improvement percentage range would be from $25 \%$ to $75 \%$. These points of improvement may help UM to execute meaningful improvement measures around the campus and to start to witness some electricity consumption reduction. In addition to the energy management matrix, establishing the baseline carbon emission rate for the whole campus is important to present an overall effect of the large electricity consumption that has taken place over the years at UM and as basis for the reduction of carbon emission to help mitigate climate change and related environmental issues. Although mitigation of climate change is intangible and the achievement is subjective, the reduction in carbon emission is finite and can help to establish the baseline campus-wide yearly carbon emission as basis for an energy efficiency policy. 
PLANNING MALAYSIA

Sustainable Urban Development

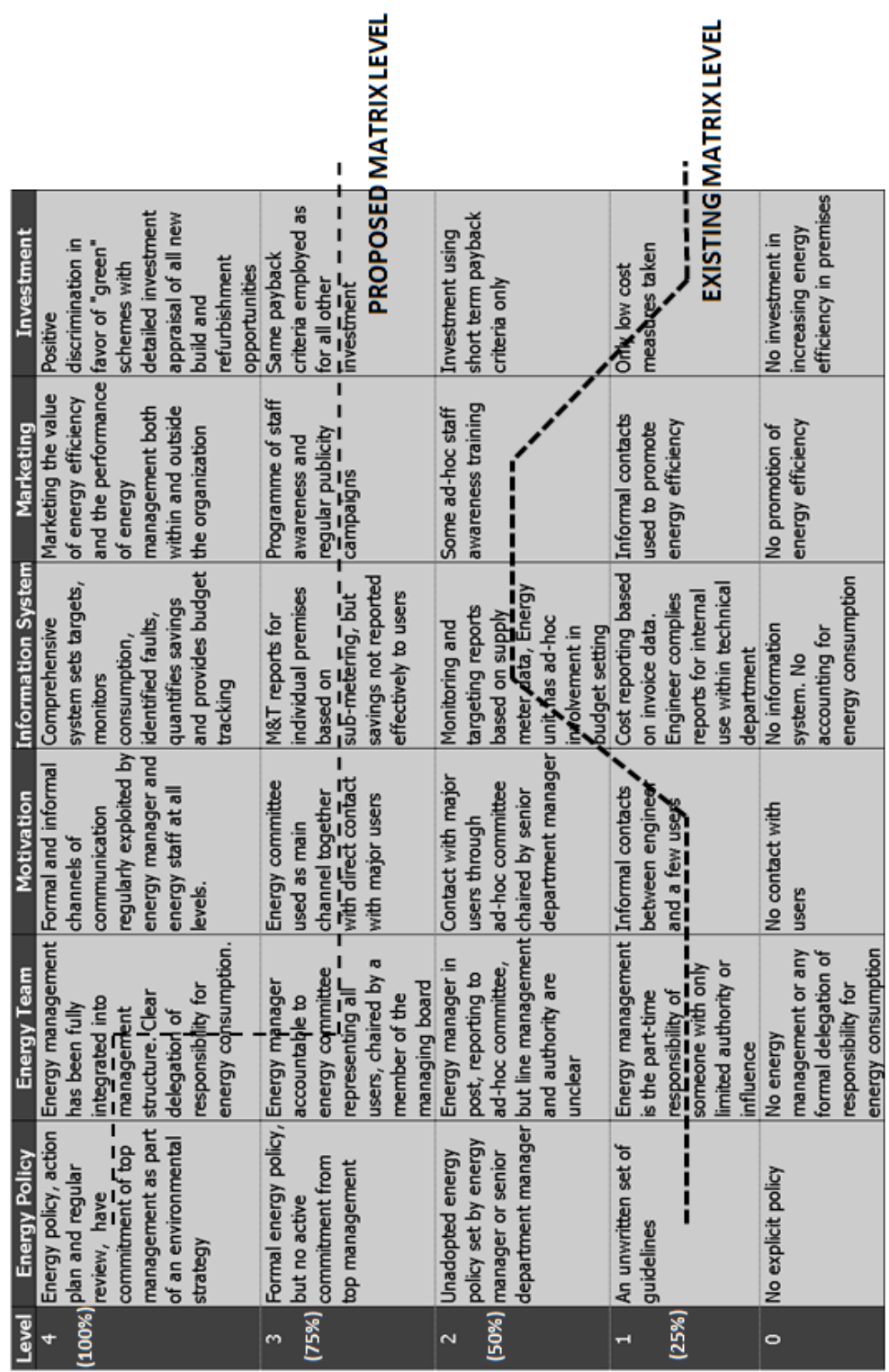

Figure 2: UM EMM adopted from AEMAS

Between 2007 and 2013, the amount of carbon emission (in $\mathrm{kg} \mathrm{CO}_{2}$ ) for the whole UM campus had increased by $9.7 \%$ on average per year (Table 1 ). Ongoing new-building developments on campus such as new faculty buildings and research facilities will definitely increase the demand for electricity further and increase the overall carbon emission. 
Muhammad Azzam Ismail, Karam M. Al-Obaidi \& Raha Sulaiman

Energy Efficiency Policy for Existing Typical Campus Buildings in the University of Malaya

Table 1: UM electricity consumption 2007-2013

\begin{tabular}{|cccccc}
\hline Year & $\begin{array}{c}\text { Average } \\
\text { monthly } \\
\text { electricity } \\
\text { consumption } \\
\text { (kWh) }\end{array}$ & $\begin{array}{c}\text { Average } \\
\text { monthly } \\
\text { maximum } \\
\text { demand } \\
\text { (kWh) }\end{array}$ & $\begin{array}{c}\text { Yearly electricity } \\
\text { consumption(kWh) }\end{array}$ & $\begin{array}{c}\text { Yearly } \\
\text { carbon } \\
\text { emission } \\
\text { (kgCO) }\end{array}$ & $\begin{array}{c}\text { Yearly } \\
\text { incremental } \\
\text { increase in } \\
\text { carbon } \\
\text { emission } \\
(\%)\end{array}$ \\
\hline $\mathbf{2 0 0 7}$ & $5,893,910.50$ & $17,525.17$ & $70,726,926$ & $48,306,490$ & - \\
\hline $\mathbf{2 0 0 8}$ & $6,015,536.17$ & $17,715.33$ & $72,186,434$ & $49,303,334$ & 9.8 \\
\hline $\mathbf{2 0 0 9}$ & $6,083,971.00$ & $18,023.08$ & $73,007,652$ & $49,864,226$ & 9.9 \\
$\mathbf{2 0 1 0}$ & $6,313,539.25$ & $18,565.92$ & $75,762,471$ & $51,745,768$ & 9.6 \\
\hline $\mathbf{2 0 1 1}$ & $6,335,642.17$ & $18,803.50$ & $76,027,706$ & $51,926,923$ & 10.0 \\
\hline $\mathbf{2 0 1 2}$ & $6,680,434.33$ & $19,713.67$ & $80,165,212$ & $54,752,840$ & 9.5 \\
\hline $\mathbf{2 0 1 3}$ & $7,086,024.67$ & $20,663.92$ & $85,032,296$ & $58,077,058$ & 9.4 \\
\hline
\end{tabular}

\section{ENERGY MANAGEMENT COMMITTEE (EMC)}

The best way to achieve the improved "Energy Policy" matrix level is to first set up an EMC at the university's top management level. This committee must have the mandate by the UM Board of Directors to implement a UM EE policy and to conduct various EE improvement measures around the campus with full administrative, financial, and technical supports.

At the faculty level, a similar EM Committee hierarchy can be adopted, where the Energy Action Centre (EAC) Chairman must be created to ensure that the chain of command is not broken and that the UM EE policy can be implemented effectively. The EAC Chairman must always be the Dean, and the Energy manager must always be the Deputy Dean (Research and Development), who has direct command of the faculty's amenities, as shown below in Figure 3 and Table 2 .

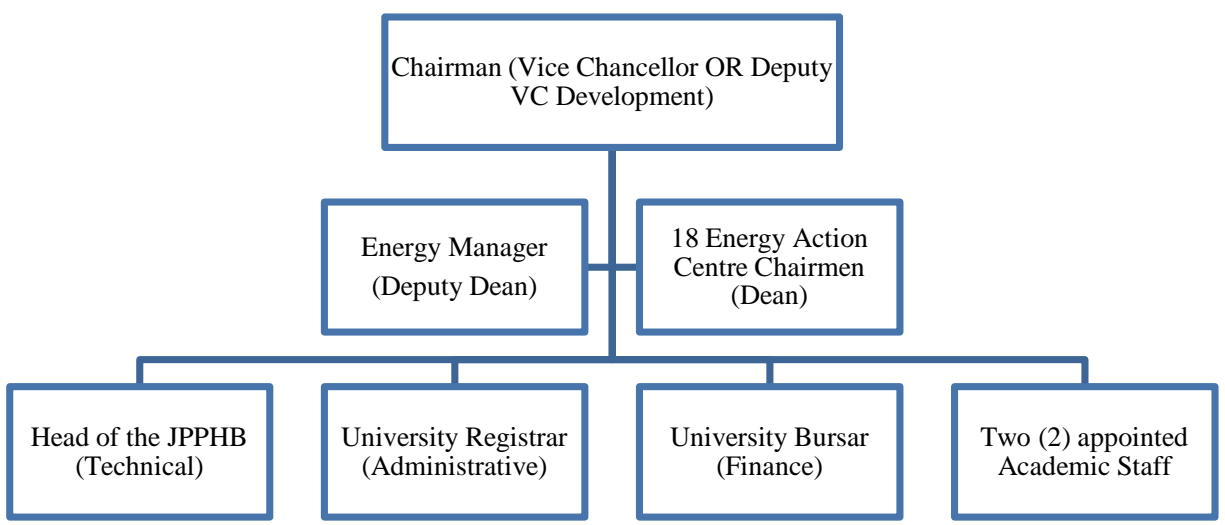

Figure 3: EMC at top level university management 
PLANNING MALAYSIA

Sustainable Urban Development

Table 2: Roles and responsibilities of the EMC at top university/faculty level

\begin{tabular}{|c|c|}
\hline $\begin{array}{c}\text { EM } \\
\text { COMMITTEE }\end{array}$ & ROLES AND RESPONSIBILITIES \\
\hline $\begin{array}{l}\text { Chairman } \\
\text { (VC \& Dean } \\
\text { Level) }\end{array}$ & $\begin{array}{l}\text { - Have full authority to make decisions to allocate resources including } \\
\text { manpower, machine, and budget to implement energy management } \\
\text { system to achieve the target stated in the energy policy }\end{array}$ \\
\hline $\begin{array}{l}\text { Energy Manager } \\
\text { (Deputy Dean) }\end{array}$ & $\begin{array}{l}\text { - Understands the energy consumption process of the whole department } \\
\text { - Coordinates with all sections to implement the energy management } \\
\text { system }\end{array}$ \\
\hline Technical Staff & $\begin{array}{l}\text { - Have authority to control operations in their section } \\
\text { - Have good technical knowledge of equipment, utilities, and processes } \\
\text { and energy efficiency technology } \\
\text { - Understand energy consumption of each area/process }\end{array}$ \\
\hline $\begin{array}{l}\text { Administrative } \\
\text { and Finance } \\
\text { Staff }\end{array}$ & $\begin{array}{l}\text { - } \quad \text { Have authority to control the operation for each area } \\
\text { - } \quad \text { Develop guidelines of working manual and tools } \\
\text { - } \quad \text { Participate in assessment of energy management performance }\end{array}$ \\
\hline $\begin{array}{c}\text { Other } \\
\text { Representatives }\end{array}$ & - Stakeholder representatives and EM Committee liaison officers \\
\hline
\end{tabular}

\section{ENERGY SAVINGS TARGET AND PLAN}

The university could start with an energy savings target of 5\% per year. This target is significantly in line with the existing Malaysian government's own energy consumption reduction target of 5\% per annum. Although this target seems low, with continuous and sustained effort over many years, it will result in substantial cost savings without major disruption to the existing university management system and maintenance budget.

In meeting the projected energy savings target, large-scale improvement measures (IM) must be planned and implemented campus-wide. IM projects at the university level can include the installation of electricity sub-meters at major buildings around the campus, organization of energy efficiency, campus-wide conservation awareness campaigns with the active participation of students and staff, and approval of specific improvement measures at the faculties.

\section{Creation of Energy Management Working Procedures}

EMCs at the top level university management and at various faculties must practice an energy management system similar to the quality management system or ISO system with various work processes, reviews, and other elements. The practice of such a system will inculcate a sense of responsibility showing that energy savings must be achieved consistently throughout the whole organization. For instance, achievements beyond the expected 5\% yearly targets should be rewarded with financial incentives to implement further improvement measures. Alternatively, yearly awards can be created for the best-performing faculties. 
Muhammad Azzam Ismail, Karam M. Al-Obaidi \& Raha Sulaiman

Energy Efficiency Policy for Existing Typical Campus Buildings in the University of Malaya

In ensuring the integrity and culpability of each improvement measure, audits similar to ISO audits of UM's curriculum and administrative processes should be conducted. Similar to the requirements of ISO, records are needed throughout the energy management process, especially at the faculties. At the top management level, committee members would deliberate over proposals for improvement measures from various faculties and yearly energy savings target, considering the finances and administrative abilities of the university. However, discussions in specific faculty-level EMCs should concentrate on planned improvement measures, the allowable budget, and outcomes or reviews of completed projects (Table 3 ).

Table 3: Documents needed for the operationalization of energy management at faculty level

\begin{tabular}{|c|c|c|}
\hline No. & $\begin{array}{l}\text { Document } \\
\text { type }\end{array}$ & Description and contents of document \\
\hline 1 & $\begin{array}{l}\text { Operating } \\
\text { guideline } \\
\text { (OG) }\end{array}$ & $\begin{array}{l}\text { - } \quad \text { Objectives of the OG } \\
\text { - } \quad \text { Scope of the OG } \\
\text { - } \quad \text { List of standards and reference documents } \\
\text { - } \quad \text { Normal working procedures to control energy consumption of faculty } \\
\text { Working forms and documents }\end{array}$ \\
\hline 2 & $\begin{array}{l}\text { Work } \\
\text { instruction } \\
\text { (WI) }\end{array}$ & $\begin{array}{l}\text { - Set of instructions to guide the implementation of individual } \\
\text { improvement measures } \\
\text { - Troubleshooting guide } \\
\text { - List of available equipment for energy auditing and other processes }\end{array}$ \\
\hline 3 & $\begin{array}{l}\text { Log sheets } \\
\text { (LS) }\end{array}$ & $\begin{array}{l}\text { - Recording of daily electricity consumption according to areas in a } \\
\text { building or major mechanical and electrical equipment }\end{array}$ \\
\hline
\end{tabular}

\section{IMPLEMENTATION OF IMROVEMENT MEASURES AT UM}

Part of the objectives of study was to simulate the implementation of improvement measures at a selected faculty to demonstrate the applicability and functionality of the whole EM-WP. The buildings selected were part of the same faculty, until very recently, the ownership of one of the blocks was transferred to a different faculty. This particular case study has two (2) blocks that can be labelled as EACs.

An EAC is a small part of the organization that can effectively control the overall energy consumption. The number of EACs will depend on the size and condition of the organization. The Faculty of Built Environment (FBE) has two blocks with a total of four wings (Figure 4). The main block at the faculty has been identified as EAC 1, whereas the surveyor's block is EAC 2. Existing available data and information of each EAC are tabulated in Table 2. After the ET \& P in step $\mathrm{G}$ is set up, the EMC must allocate the responsibility to each EAC 
PLANNING MALAYSIA

Sustainable Urban Development

to identify the measures in their areas. The target allocation is based on their respective energy consumption.

To identify an effective energy management plan, both EACs will use the recommended internal WP or EAC-WP, as outlined in Figure 5. This WP will help the EACs to identify improvement measures to control energy consumption in their respective areas. Through the EAC-WP, each improvement measure can be properly implemented, monitored, and audited. As part of the EAC-WP, the OG, Work Instruction (WI), and Log Sheet (LS), as in Table 3, must be created and used.

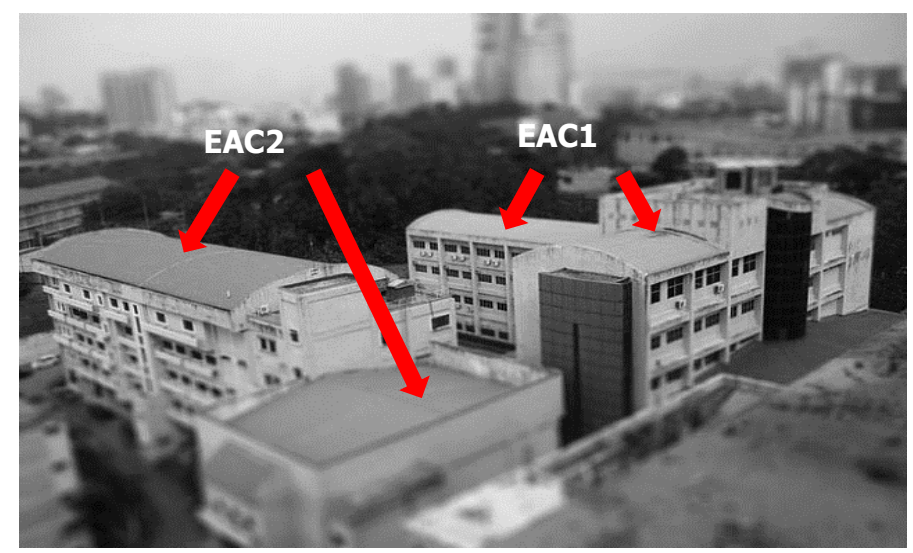

Figure 4: Blocks of FBE and the designated EAC

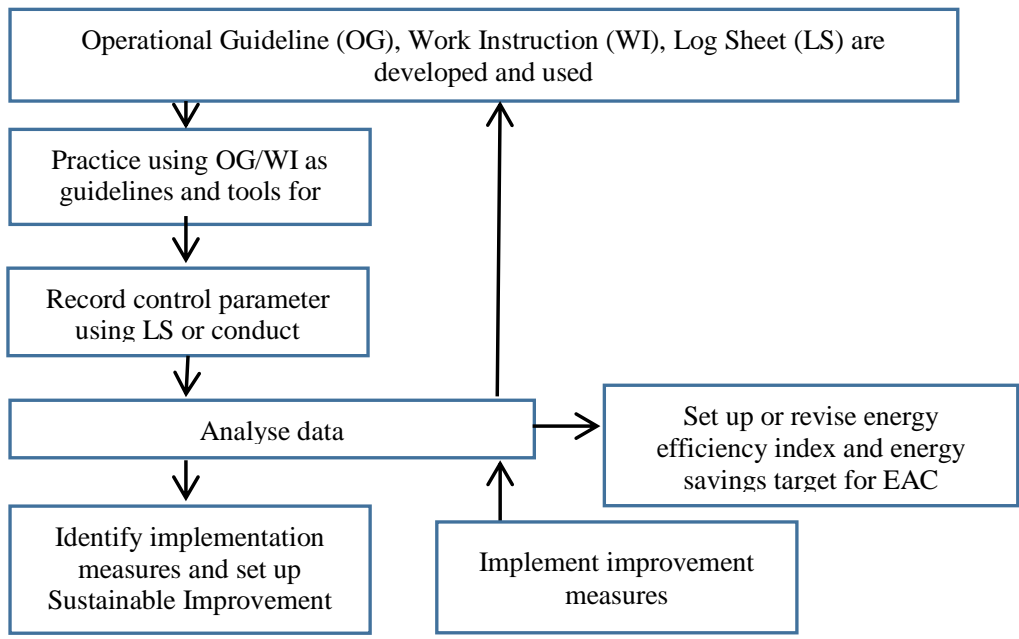

Figure 5: EAC energy management working procedure (EM-WP) 
Muhammad Azzam Ismail, Karam M. Al-Obaidi \& Raha Sulaiman

Energy Efficiency Policy for Existing Typical Campus Buildings in the University of Malaya

Energy savings can be achieved from three (3) levels of practical measures: zero/low cost (housekeeping), medium cost investments, and high cost investments. At the initial stage, the faculty could implement low cost and medium cost measures to improve the EEs of EAC1 and EAC2. This faculty targets to achieve at least 5\% of energy savings, following UM's proposed yearly energy savings target. Low-cost measures represent a move toward technology solution but with substantial input from building occupants. Table 4 below shows proposed improvement measures that must be approved by the faculty's EMC and could be implemented over a set period of time.

Table 4: Proposed improvement measures with details for EAC1 and EAC2

\begin{tabular}{|c|c|c|c|}
\hline & IM No. & Improvement Measure details & Budget \\
\hline \multirow[t]{4}{*}{$\begin{array}{l}\text { EAC 1 } \\
\text { (SIT1) }\end{array}$} & IM1-1 & $\begin{array}{l}\text { Installation of weather strips } \\
\text { Providing glass doors with both horizontal and } \\
\text { vertical weather stripping ( } 3 \text { units): } \\
\text { - RM } 25.00 / \mathrm{p} \\
\text { Providing timber doors with bottom door weather } \\
\text { stripping (65 units): } \\
\text { - RM } 1.50 / \mathrm{m}\end{array}$ & RM 250.00 \\
\hline & IM2-1 & $\begin{array}{cc}\text { - } & \text { Installation of timer to centralised a/c system } \\
& \text { Timer (RM480.00 x } 4 \text { AHUs) }\end{array}$ & RM $1,920.00$ \\
\hline & IM3-1 & 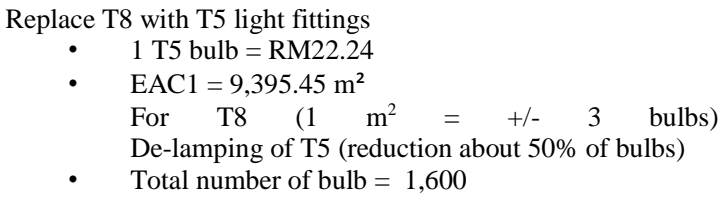 & RM 35,584.00 \\
\hline & IM4-1 & $\begin{array}{l}\text { Setting all split air-conditioning units at } 24^{\circ} \text { and confiscating all } \\
\text { remote controls. } \\
\text { Wiring and setting the air-conditioning units = } \\
\quad \text { RM } 80.00 / \text { unit } \\
\text { - Number of split air-conditioning units = 94 } \\
\text { Maintaining centralised a/c system }\end{array}$ & $\mathrm{RM} 7,520.00$ \\
\hline \multirow[t]{3}{*}{$\begin{array}{l}\text { EAC 2 } \\
\text { (SIT2) }\end{array}$} & IM1-2 & $\begin{array}{l}\text { Installation of weather strips. } \\
\text { Providing glass doors with bottom, up and centre } \\
\text { weather stripping }(8 \text { units) } \\
\text { - RM } 25.00 / \mathrm{p} \\
\text { Providing timber doors with bottom door weather } \\
\text { stripping (75 units): } \\
\text { - RM } 1.50 / \mathrm{m}\end{array}$ & RM 450.00 \\
\hline & IM2-2 & 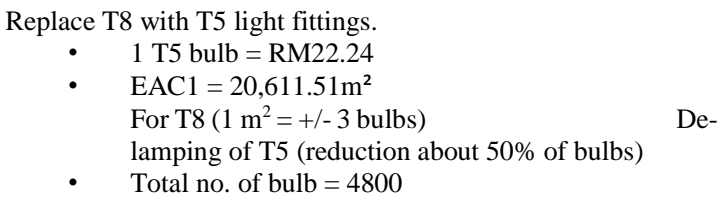 & RM $77,840.00$ \\
\hline & IM3-2 & $\begin{array}{l}\text { Setting all split air-conditioning units at } 24^{\circ} \text { and confiscating all } \\
\text { remote controls. } \\
\text { - Wiring and setting the air-conditioning units = } \\
\text { RM } 80.00 / \text { unit } \\
\text { - Number of split air-conditioning units }=81\end{array}$ & RM $6,480.00$ \\
\hline
\end{tabular}




\section{IM1 - Installation of weather strip}

Weather stripping is a material used to seal gaps around windows and exterior doors. Caulking seals the small gaps at doors; weather-stripping seals around them can help to make the building airtight.

\section{IM2 - Installation of timer at AHU}

Currently, the centralized air-conditioning system only supplies cool air to EAC 1 , which is the main block. The air-conditioning system starts at 8:00 am and shuts down at 10:00 pm during the weekdays and 9:00 pm on Saturdays. This operation resulted in major energy wastage and increased energy bills. Four (4) AHUs are found in EAC1, distributing cool air to each floor. A timer can automatically switch air conditioners on and off, which means that an occupant can fall asleep with a unit turned on, but the unit can automatically shut down after an hour or so.

\section{IM3 - Replace T8 with T5 lighting fixtures}

In proposing an improvement toward energy efficient buildings, the lighting system must be changed to a more energy efficient lighting such as T5. The T5 adapter has its own extremely efficient built-in ballast. This component can produce more light, in particular more natural light, than before while saving about $79 \%$ on lighting cost. Table 5 shows additional information about T5 and T8.

Table 5: Specifications of the T5 and T8 Fluorescent Light Bulb

\begin{tabular}{|c|c|c|c|c|c|c|c|c|}
\hline 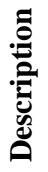 & 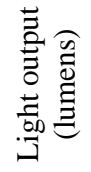 & 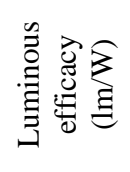 & 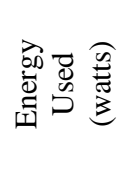 & 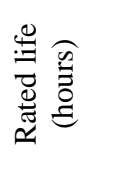 & 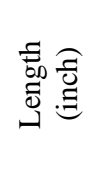 & 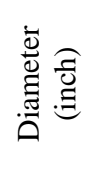 & 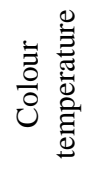 & 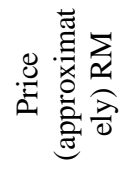 \\
\hline T8 & 1900 & 80 & 36 & 15,000 & 36 & 1 & 4100 & 12.00 \\
\hline T5 & 2100 & 1001 & 21 & 20,000 & 34 & 0.625 & 3500 & 22.00 \\
\hline
\end{tabular}

\section{IM 4 - Setting all existing split air-conditioning units}

In setting the temperature to be consistent at $24^{\circ} \mathrm{C}$ at all times, minor re-wiring works will be conducted at the indoor unit of the split system. The occupant/user will only have to turn on the air-conditioning system with the existing switch. All individual remote controls will be confiscated. This improvement measure is also in accordance with KETTHA's requirements to have $24^{\circ} \mathrm{C}$ in all government buildings (REF). 
Muhammad Azzam Ismail, Karam M. Al-Obaidi \& Raha Sulaiman

Energy Efficiency Policy for Existing Typical Campus Buildings in the University of Malaya

\section{IM5 - Maintenance of centralized air-conditioning system}

Regular and planned preventive maintenance management is the best solution to maintain the performance of the air-conditioning systems in any building. This maintenance avoids failures in the operation of the units. Failures include the following: outdoor fan does not run, compressor does not run, no cool air felt, excessive cooling, and others.

\section{MONITORING AND ASSESSMENT OF IMPROVEMENT MEASURE RESULTS}

As a guide in implementing all improvement measures, a Gantt chart shown in Figure 6 must be created by the faculty EMC to ensure the delivery of planned projects.

\begin{tabular}{|c|c|c|c|c|c|c|c|}
\hline $\begin{array}{ll}\text { Tasks } & \text { Month } \\
\end{array}$ & $\begin{array}{c}\text { Month } \\
1\end{array}$ & $\begin{array}{l}\text { Month } \\
2\end{array}$ & $\underset{3}{\text { Month }}$ & $\begin{array}{c}\text { Month } \\
4\end{array}$ & $\begin{array}{l}\text { Month } \\
5\end{array}$ & $\begin{array}{l}\text { Month } \\
6\end{array}$ & $\begin{array}{c}\text { Month } \\
7\end{array}$ \\
\hline $\begin{array}{l}\text { A. Appoint Energy } \\
\text { Manager }\end{array}$ & & & & & & & \\
\hline $\begin{array}{l}\text { B. Set up Energy } \\
\text { Management } \\
\text { Committee (EMC) }\end{array}$ & & & & & & & \\
\hline $\begin{array}{ll}\text { C. Evaluate Energy } \\
\text { Management status }\end{array}$ & & & & & & & \\
\hline $\begin{array}{l}\text { D. Set up Energy } \\
\text { Management } \\
\text { component }\end{array}$ & & & & & & & \\
\hline $\begin{array}{l}\text { E. Set Energy Target and } \\
\text { Plan }\end{array}$ & & & & & & & \\
\hline $\begin{array}{l}\text { F. Assign saving target to } \\
\text { EAC }\end{array}$ & & & & & & & \\
\hline G. Identification of IMs & & & & & & & \\
\hline $\begin{array}{l}\text { H. Presentation of IMs } \\
\text { and budget to the EMC }\end{array}$ & & & & & & & \\
\hline I. Implementation of IMs & & & & & & & \\
\hline $\begin{array}{ll}\text { J. } & \text { Monitoring and } \\
\text { assessment of IMs }\end{array}$ & & & & & & & \\
\hline
\end{tabular}

Figure 6: Gantt chart for the implementation of the EM-WP

After all improvement measures have been successfully implemented, the EMC will monitor and assess the implementation results. This monitoring will be done at two (2) levels:

$>$ Level 1-Faculty/Organization

- To assess the performance of the implementation of the EM-WP

- To assess the effect on the overall EEI

Level 2 -EACs

- To assess the performance of ECMs and the daily practice within each EAC. This assessment is to be conducted every month for six 
(6) months after the completion of the system preparation and the implementation of the ECMs.

The monitoring and assessment at both levels can be conducted through the following:

- Internal audit of IMs

- External audit of IMs by EMC from other faculties (third party) and student representatives (second party)

\begin{tabular}{|c|c|c|c|c|c|c|c|c|c|c|c|c|c|c|c|c|}
\hline \multirow[b]{2}{*}{$\begin{array}{l}\text { Month } \\
\text { Measur } \\
\text { es }\end{array}$} & \multicolumn{4}{|c|}{ Month 1} & \multicolumn{4}{|c|}{ Month 2} & \multicolumn{4}{|c|}{ Month 3} & \multicolumn{4}{|c|}{ Month 4} \\
\hline & $\begin{array}{l}W \\
1\end{array}$ & $\begin{array}{l}\text { W } \\
2\end{array}$ & $\begin{array}{l}\text { W } \\
3\end{array}$ & $\begin{array}{l}\text { W } \\
4\end{array}$ & $\begin{array}{l}\text { W } \\
1\end{array}$ & $\begin{array}{l}\text { W } \\
2\end{array}$ & $\begin{array}{l}\text { W } \\
3\end{array}$ & $\begin{array}{l}\text { W } \\
4\end{array}$ & $\begin{array}{l}W \\
1\end{array}$ & $\begin{array}{l}\text { W } \\
2\end{array}$ & $\begin{array}{l}\text { W } \\
3\end{array}$ & $\begin{array}{l}\text { W } \\
4\end{array}$ & $\begin{array}{l}\text { W } \\
1\end{array}$ & $\begin{array}{l}\text { W } \\
2\end{array}$ & $\begin{array}{l}W \\
3\end{array}$ & $\begin{array}{l}\text { W } \\
4\end{array}$ \\
\hline IM1-1 & & & & & & & & & & & & & & & & \\
\hline IM2-1 & & & & & & & & & & & & & & & & \\
\hline IM3-1 & & & & & & & & & & & & & & & & \\
\hline IM4-1 & & & & & & & & & & & & & & & & \\
\hline IM5-1 & & & & & & & & & & & & & & & & \\
\hline IM1-2 & & & & & & & & & & & & & & & & \\
\hline IM2-2 & & & & & & & & & & & & & & & & \\
\hline IM3-2 & & & & & & & & & & & & & & & & \\
\hline $\begin{array}{l}\text { Audit } \\
\text { of IM } \\
\text { results }\end{array}$ & & & & & & & & & & & & & & & & \\
\hline
\end{tabular}

Figure 7: Gantt chart for the implementation of IMs

\section{EXPECTED RESULTS}

The EMC at the studied faculty could expect that within 3 years of the implementation of this simulated energy management plan, the faculty's Energy Matrix will be improved.

\section{Expected Cost Requirements}

The expected cost that the studied faculty needs to invest is based on the expenditures needed in IM. Table 6 below summarizes the expected cost of this implementation.

Table 6: Summary of expected cost requirement

\begin{tabular}{ccc}
\hline No. & Task & Expected cost (RM) \\
\hline 1 & Energy Conservation Measures (ECM) & $135,044.00$ \\
2 & Overhead (20\% from item 1) & $27,008.80$ \\
\hline & TOTAL & $\mathbf{1 6 2 , 0 5 2 . 8 0}$ \\
\hline
\end{tabular}


Muhammad Azzam Ismail, Karam M. Al-Obaidi \& Raha Sulaiman

Energy Efficiency Policy for Existing Typical Campus Buildings in the University of Malaya

\section{Net-cost Benefits}

The actual electricity bill is not known; therefore, the electricity bill is calculated through estimated figures from the technical staff of FBE, who is responsible for the maintenance and use of the building's facilities. Based on the estimated annual energy consumption of the studied faculty at $240,000 \mathrm{kWh} /$ month and the electricity tariff at RM0.43 per $\mathrm{kWh}$, the overall electricity bill for the whole studied faculty is RM 1,238,400 per year. To estimate the return on investment and the overall payback period, the EMC calculated the estimated benefit that this faculty can gain based on payback period and energy savings target.

\section{Payback Period}

- Assume the annual electricity cost for the whole building = RM 1,238,400.00 (This value includes all mechanical and electrical equipment.)

- Electricity bill for air-conditioning system (estimated at $50 \%$ from total $)=$ RM 619,200.00

Through installing a timer, performing weather stripping, and performing regular maintenance of the air-conditioning system, an estimated $10 \%$ reduction in energy consumption can be achieved. Therefore,

- $10 \%$ reduction from RM 619, 200.00

$$
=\text { RM 61, } 920.00
$$

- Electricity bill for lighting system (estimated at $20 \%$ from total)

$$
=\mathrm{RM} 247,680.00
$$

Through the de-lamping of the lighting fixtures, an estimated $50 \%$ reduction in energy consumption can be achieved. However, this implementation will be carried in stages and must be completed within three years. Therefore,

1st year reduction $\quad=\quad \mathrm{RM} 41,280.00$

2nd year reduction $\quad=\quad$ RM 82,560.00

3rd year reduction $\quad=\quad \mathrm{RM} \mathrm{123,840.00}$

- The expected cost requirement for the IM

$=\mathrm{RM} 162,052.80$ Total saving for electricity bill (based on 1st year reduction)

$=\mathrm{RM} 103,200.00$.

- Overall payback period (based on 1st year reduction)

Payback period $=\frac{\text { Installation cost }(\mathrm{RM} \mathrm{162,052.80)}}{\text { Overall reduction/saving (RM 103,200.00) }}=19$ months 
PLANNING MALAYSIA

Sustainable Urban Development

\section{Energy Savings Target (\%)}

In three years, the studied faculty could target to achieve a 5\% of reduction in yearly energy consumption and electricity bills. Calculating its initial (1st year) energy saving target involves the following:

Estimated annual electricity bill $\quad=\quad \mathrm{RM} 1,238,400.00$

Estimated reduction in electricity bill $=$ RM 103,200.00

Energy savings target $=$

Estimated reduction (RM 103,200.00) $\times 100=8.333 \%$

Estimated annual bill (RM 1,238,400.00)

The studied faculty will successfully achieve its 5\% energy and cost saving target approximately within one (1) year of the implementation of the proposed improvement measures.

\section{CONCLUSION}

This study has presented the chronological process of setting up a functional energy management system for a large university campus that can be implemented as soon as concrete confidence and commitment from the top management of the university is gained. This energy management system follows an established system created by AEMAS and is in line with the existing quality management system at UM. In other words, this new energy management system is a new dimension to the existing ISO system that the university has already practiced for many years in its curriculum and administrative processes. The presentation of a specific faculty's improvement measures, budget, and timeline indicated that with only the implementation of low-cost measures, a yearly energy savings target of $5 \%$ can be easily achieved with an ROI of one (1) year.

\section{ACKNOWLEDGEMENTS}

The authors would like to acknowledge the funding received for this study through the UM flagship project number FL-027 under the purview of the Sustainability Science Cluster, UM. The authors would also like to thank all individuals who have contributed to the successful gathering of all information for this study. 
Muhammad Azzam Ismail, Karam M. Al-Obaidi \& Raha Sulaiman

Energy Efficiency Policy for Existing Typical Campus Buildings in the University of Malaya

\section{REFERENCES}

Association of Water and Energy Research Malaysia's (AWER) (2014). Energy efficiency in Malaysia sustainable production and consumption: Phasing-out Malaysia's non-energy efficient products.

Ayres, I., Raseman, S. \& Shih, A. (2013). Evidence from two large field experiments that peer comparison feedback can reduce residential energy usage. Journal of Law, Economics and Organization, 29(5), 992-1022.

Clean Development Mechanism (CDM) Capacity Building Project. Ministry of Energy, Water and Communications of Malaysia.

Hignite, K. (2008). Seeking a smaller footprint. Business Officer, 42, 63-72.

Levy, B. L. \& Marans, R. W. (2012). Towards a campus culture of environmental sustainability: recommendations for a large university. International Journal of Sustainability in Higher Education, 13(4), 365-377.

PTM and DANIDA. (2006). Study on Grid Connected Electricity Baselines in Malaysia. Marans, R. W. \& Edelstein, J. Y. (2010). The human dimension of energy conservation and sustainability: A case study of the University of Michigan's energy conservation program. International Journal of Sustainability in Higher Education, 11(1), 6-18. 